\title{
Audit of Complications in an Otolaryngology Led Skull-Base Surgical Practice
}

\author{
Uma Patnaik ${ }^{1,2}$ Smriti Panda ${ }^{1} \quad$ Alok Thakar $^{1}$ \\ ${ }^{1}$ Department of Otolaryngology-Head and Neck Surgery, \\ All India Institute of Medical Sciences, New Delhi, India \\ 2 Department of Otolaryngology-Head and Neck Surgery, \\ Army Hospital, Research and Referral, New Delhi, India
}

\begin{abstract}
Address for correspondence Alok Thakar, MS, FRCSed, Department of Otolaryngology and Head-Neck Surgery, All India Institute of Medical Sciences, New Delhi, 110029, India (e-mail: drathakar@gmail.com).
\end{abstract}

J Neurol Surg B 2019;80:586-592.

\begin{abstract}
Objective This study was aimed to classify and study complications of surgery of the cranial base, primarily from an otorhinolaryngology perspective.

Design This study was designed with consecutive cohort of skull base surgical cases. Setting Tertiary referral academic center.

Participants Patients having skull-base surgery at a otorhinolaryngology based skullbase unit, from 2002 to 2015.

Main Outcome Measures Enumeration of complications is the main outcome of this study. Surgical procedures, categorized for complexity as per a unified system, are applicable to endoscopic and open procedures. Complications were categorized as per the British Association of Otolaryngologists coding of surgical complications. Complication classified as major if life-threatening, causing permanent disability, or compromising the result of surgery. Results A total of 342 patients $(n=342)$ were operated; 13 patients' records were excluded due to $<6$ months posttreatment follow-up. The study group constituted 204 anterior skull-base (endoscopic, 120; open/external, 84) and 125 lateral skull-base procedures. Complication rates noted to increase in both groups with increasing complexity of surgical intervention. Anterior skull-base surgery (total complications, $11 \%$; major, $3 \%$; death, $0.5 \%$ ) noted to have significantly less surgical complications than lateral skull-base surgery (total complications, 33\%; major, $15 \%$; death, 1.6\%; $p<0.001$ ). Among the anterior procedures no significant difference noted among endoscopic and external approaches when compared across similar surgical complexity.

Keywords

- skull base

- complications

- skull-base surgery

- mortality

Conclusion Despite improvement in surgical and perioperative care, the overall major complication rate in a contemporary otolaryngology led, primarily extradural, skull-base practice is noted at $8 \%$. Perioperative mortality, though rare, was encountered in $1 \%$. A standard method for categorization of surgical complexity and the grade of complications as reported here is recommended.
\end{abstract}

\section{Introduction}

Surgery of the skull-base forms is a challenging segment in otorhinolaryngology practice. Treatment is undertaken for complex and varied pathologies. Advances in diagnostic radiology, interventional radiology, neuronavigation, nerve monitoring, surgical instrumentation, and postsurgical care have transformed both the scope and the safety of modern skull-base surgical practice. Nevertheless, complications are a frequent reality.

The exact definitions of what constitutes skull-base surgery and what should and should not be included under this label received

June 24, 2018

accepted after revision

November 14, 2018

published online

December 26, 2018 (c) 2019 Georg Thieme Verlag KG Stuttgart · New York
DOI https://doi.org/ 10.1055/s-0038-1676793. ISSN 2193-6331. 
remain contentious. The gamut of complications can vary widely depending on the case mix in a particular practice. Previous reports have documented the individual complications of endoscopic, anterior external, lateral, and pediatric skull-base surgery. ${ }^{1-7}$

This report attempts to standardize and compare surgical complexity and surgical complications across the entire surgical spectrum of skull base surgery (endoscopic anterior, open anterior, and open lateral) as encountered at a contemporary otolaryngology led skull-base surgery practice. Surgical procedures are classified as per approach and complexity $^{8,9}$ and complications classified as per a patient oriented, standard reporting format. ${ }^{10}$

\section{Methods}

A retrospective chart review of all patients with skull-base procedures was undertaken at the Department of Otolaryngology and Head-Neck Surgery under the care of the senior author from January 2002 to March 2015. Appropriate Institutional permissions were obtained. Follow-up data were collated from chart review, follow-up records, followup reviews, and telephonic follow-ups.

The following criteria were used to define the study population:

Inclusion criteria: All patients of who underwent surgery for lesions of the skull-base were included. These included external, endoscopic as well as combined approaches.

Exclusion criteria: Patients with less than 6 months follow-up were excluded from the study.

The charts and follow-up records of patients in the study population were evaluated for demographic data, diagnosis, the site of lesion, surgical approach, surgery undertaken, and complications encountered.

\section{Categorization of Surgical Procedures}

Surgical approaches were categorized as endoscopic endonasal, external anterior, and external lateral.
Surgical procedures were further graded as per the surgical complexity. Endoscopic endonasal procedures have been previously classified for degree of complexity by Snyderman et al. ${ }^{9}$ As per this classification, level I procedures are the initial sinus access procedures which are precursors to subsequent skullbase procedures (e.g., endoscopic sphenoid and frontal sinus access and sphenopalatine artery ligation). The specific skullbase procedures are classified as level II-V in graded degrees of complexity progressing along level II (skull-base bone exposure, minor dural leak closure, intrasellar pituitary), level III (significant dural exposure, extradural intracranial procedures, extrasellar pituitary), level IV (intradural procedures, major carotid exposure), and level V (vascular malformations and highly vascular tumors, aneurysms). Drawing on this above classification, a similar grading was undertaken for external anterior and external lateral procedures and the same is indicated in -Table 1. Highly vascular tumors were classified as level V by Snyderman et al but highly vascular tumors with appropriate embolization have been classified as level IV in this analysis as the majority of such tumors (juvenile angiofibroma and glomus jugulare tumors) are currently managed with preoperative embolization prior to surgery.

\section{Surgical Techniques and Approaches}

The surgical procedure was tailored depending on the site and extent of lesion. Presurgical embolization, neuronavigation, cranial nerve monitoring, and postsurgical ventilation were undertaken as per requirement. All surgeries were undertaken under the care of the otolaryngology service and led by the senior author (A.T.). Collaboration with neurosurgery was undertaken as and when appropriate and particularly for level IV procedures. Level V procedures are routinely undertaken under the neurosurgery service and do not form part of this particular dataset.

\section{Categorization of Complications}

The complications were classified as minor, intermediate, major, and death as in accordance with the codes prepared

Table 1 Categorization of complexity of surgical procedure and severity of complication

Categorization of complexity of skull-base surgical procedure (applicable to all approaches, i.e., endonasal endoscopic, external anterior, and external lateral)

\begin{tabular}{|l|l|}
\hline Level I & Precursor surgical procedures preceding skull-base access \\
\hline Level II & Skull-base bone exposure, minor dural exposure/dural leak closure; intrasellar pituitary \\
\hline Level III & significant dural exposure, extradural intracranial procedures, extrasellar pituitary \\
\hline Level IV & Intradural procedures, major carotid exposure, highly vascular tumors (appropriate embolization) \\
\hline Level V & Vascular malformations, aneurysms, highly vascular tumors (no or inadequate embolization) \\
\hline Categorization of surgical complications \\
\hline Minor complication & A complication which does not require treatment or delay discharge \\
\hline $\begin{array}{l}\text { Intermediate } \\
\text { complication }\end{array}$ & $\begin{array}{l}\text { A complication which delays discharge or which requires or prolongs treatment } \\
\text { but does not cause permanent disability }\end{array}$ \\
\hline Major complication & $\begin{array}{l}\text { A life threatening complication or one which causes permanent disability } \\
\text { or which compromises the result of surgery }\end{array}$ \\
\hline Death & - \\
\hline
\end{tabular}


for the British Association of Otolaryngologists for reporting on surgical complications (-Table 1). ${ }^{10}$

Expected sequelae, such as anosmia, following a traditional anterior cranio-facial resection and grade III facial weakness following a facial nerve transposition for a glomus jugulare excision were not rated as complications. All patients who underwent planned facial nerve transposition in the infratemporal approaches were counseled about postoperative facial paralysis. Recovery to grade III or better by 9 months was classified as an expected sequelae and not a complication. A grade IV or worse status at the 9-mont review was listed as a major complication.

New lower cranial nerve palsies inclusive of $\mathrm{X}$ nerve loss or section was corrected at surgery or in the early postsurgical period with a thyroplasty procedure. ${ }^{11}$ In keeping with the criteria listed in $\mathbf{- T a b l e ~} \mathbf{2}$, well rehabilitated speech and swallowing postsurgery was classified as an intermediate complication (i.e., requires treatment but does not cause permanent disability).

\section{Results}

Clinicosurgical Profile of Patients Undergoing Surgery From January 2002 to March 2015, 342 patients were operated at our otorhinolaryngology and head-neck surgery referral centre for various lesions of the skull-base. Thirteen patients were excluded from this analysis as per the exclusion criteria and 329 patients constitute the final study group.

\section{Details of Surgery}

Of the 329 patients included in the study, 204 (62\%) patients underwent surgery on the anterior skull-base and 125 (38\%) on the lateral skull-base. Among the 204 anterior procedures 120 (59\%) were purely endoscopic and 84 were open or external approaches. Endoscopic assistance was used in 17 of the 84 patients with external anterior approaches. There was intracranial intradural involvement in 21 cases (6.4\%). The details of surgical procedures as per complexity of surgery are detailed at $\mathbf{-}$ Table $\mathbf{2}$.

Table 2 Listing of complications as per categorization skull-base surgical procedures

\begin{tabular}{|c|c|c|c|}
\hline \multicolumn{3}{|c|}{ Surgical approach and complexity } & Surgical complications \\
\hline \multicolumn{4}{|c|}{ Anterior skull base } \\
\hline \multirow{3}{*}{$\begin{array}{l}\text { Endoscopic } \\
\text { endonasal } \\
\text { skull-base } \\
(n=120)\end{array}$} & $\begin{array}{l}\text { Level II } \\
(n=55)\end{array}$ & - CSF rhinorrhea repair & $\begin{array}{l}\text { Intermediate graft donor site infection (2), } \\
\text { postsurgical seizures ( } 1 \text { ), valproate toxicity (1) }\end{array}$ \\
\hline & $\begin{array}{l}\text { Level III } \\
(n=53)\end{array}$ & $\begin{array}{l}\text { - Meningocoele. enchephalocoele excision } \\
\text { - Pituitary (extrasellar) and clival tumors } \\
\text { - Optic nerve decompression } \\
\text { - Posttraumatic } \\
\text { - Skull-base fibrous dysplasia } \\
\text { - Nose and PNS tumors } \\
\text { - Mucocele with extensive dural exposure } \\
\text { - Allergic fungal rhinosinusitis -intracranial }\end{array}$ & $\begin{array}{l}\text { Minor transient CSF leak (1), } \\
\text { Intermediate CSF leak requiring repair (1), } \\
\text { postsurgical seizures ( } 1) \text {, } \\
\text { secondary hemorrhage }(1) \\
\text { Major extradural hemorrhage (1) }\end{array}$ \\
\hline & $\begin{array}{l}\text { Level IV } \\
(n=12)\end{array}$ & $\begin{array}{l}\text { - Clival chordoma/olfactory groove meningioma/ } \\
\text { olfactory Neuroblastoma (intradural) } \\
\text { - Petrous cholesterol granuloma with major ICA } \\
\text { exposure } \\
\text { - Allergic fungal rhinosinusitis with major ICA } \\
\text { exposure }\end{array}$ & $\begin{array}{l}\text { Minor secondary hemorrhage (1), } \\
\text { Major meningitis (1), } \\
\text { carotid blow-out and hemiparesis ( } 1 \text { ) }\end{array}$ \\
\hline \multirow[t]{3}{*}{$\begin{array}{l}\text { External } \\
\text { anterior } \\
\text { skull-base } \\
(n=84)\end{array}$} & $\begin{array}{l}\text { Level II } \\
(n=23)\end{array}$ & $\begin{array}{l}\text { - Osteoplastic flap } \\
\text { - Frontal sinus CSF rhinorrhea } \\
\text { - Maxillary swing } \\
\text { - Nose, PNS, Infratemporal fossa tumors }\end{array}$ & Minor transient CSF leak (1) \\
\hline & $\begin{array}{l}\text { Level III } \\
(n=28)\end{array}$ & $\begin{array}{l}\text { - Ant craniofacial resection } \\
\text { - Nose and PNS tumors } \\
\text { - Orbital tumors, intracranial-extradural } \\
\text { extension } \\
\text { - Invasive fungal granuloma with intracra- } \\
\quad \text { nial-extradural extension } \\
\text { - Maxillary swing } \\
\text { - Juvenile angiofibroma Radkowski's IIIA }\end{array}$ & $\begin{array}{l}\text { Minor transient VI } n \text { palsy (2),transient III } \\
n \text { palsy (1), } \\
\text { Intermediate, medial canthus fistula (1), } \\
\text { CSF leak requiring repair (1), } \\
\text { Major palatal perforation (1) }\end{array}$ \\
\hline & $\begin{array}{l}\text { Level IV } \\
(n=33)\end{array}$ & $\begin{array}{l}\text { - Maxillary swing/anterior craniofacial resection } \\
\text { - Juvenile angiofibroma Radkowski's IIIB (ICA } \\
\text { exposure/cavernous sinus involvement) } \\
\text { - Nasal dermoid with intracranial extension } \\
\text { - Nose and PNS malignancy with ICA exposure } \\
\text { with intradural extn./ICA abutment }\end{array}$ & $\begin{array}{l}\text { Intermediate seizure }(1) \text {, } \\
\text { Major extradural hemorrhage (1), } \\
\text { palatal perforation (1), } \\
\text { death pulmonary thromboembolism (1) }\end{array}$ \\
\hline
\end{tabular}


Table 2 (Continued)

\begin{tabular}{|c|c|c|c|}
\hline \multicolumn{3}{|c|}{ Surgical approach and complexity } & Surgical complications \\
\hline \multicolumn{4}{|c|}{ Anterior skull base } \\
\hline \multirow[t]{3}{*}{$\begin{array}{l}\text { External } \\
\text { lateral } \\
\text { skull-base } \\
(n=125)\end{array}$} & $\begin{array}{l}\text { Level II } \\
(n=16)\end{array}$ & $\begin{array}{l}\text { - CSF otorrhoea-transmastoid repair/middle } \\
\text { cranial fossa repair } \\
\text { - CSF otorrhoea-subtotal petrosectomy } \\
\text { - Skull-base osteomyelitis with medial extn. }\end{array}$ & $\begin{array}{l}\text { Minor, transient CSF leak (1), } \\
\text { Intermediate postoperative CSF leak repair (1) }\end{array}$ \\
\hline & $\begin{array}{l}\text { Level III } \\
(n=64)\end{array}$ & $\begin{array}{l}\text { - Infratemporal fossa approach of Fisch's types } \\
\text { A/B } \\
\text { - Middle ear meningioma } \\
\text { - Jugular foramen nonparaganglioma tumors } \\
\text { - Endolymphatic sac tumor } \\
\text { - Anterior petrosectomy- } \\
\text { - Cholesteatoma, skull-base osteomyelitis } \\
\text { - Orbitozygomatic subtemporal-infratemporal } \\
\text { approach } \\
\text { - Infratemporal tumors } \\
\text { - Invasive fungal granuloma } \\
\text { - Juvenile angiofibroma IIC/IIIA }\end{array}$ & $\begin{array}{l}\text { Intermediate } X \text { nerve palsy }(5),{ }^{a} \text { seizures (1), } \\
\text { Major extradural hemorrhage ( } 1) \text {, } \\
\text { VB/VC nerve section (3) }\end{array}$ \\
\hline & $\begin{array}{l}\text { Level IV } \\
(n=45)\end{array}$ & $\begin{array}{l}\text { - Infratemporal fossa approach of Fisch's types A, } \\
\text { B, and C } \\
\text { - Tympanojugular paraganglioma } \\
\text { - Orbitozygomatic subtemporal-infratemporal } \\
\text { approach } \\
\text { - Juvenile angiofibroma IIIB/ICA exposure } \\
\text { - Nasopharynx malignancy (ACC) } \\
\text { - Subtotal temporal bone resection } \\
\text { - Temporal bone malignancy } \\
\text { - Petrous apex drainage/debridement } \\
\text { - Skull-base osteomyelitis extensively abutting } \\
\text { petrous ICA } \\
\text { - Extensive petrous apicitis/tuberculosis } \\
\text { - Translabyrinthine/transotic approach } \\
\text { - Vestibular shwannoma/petrous cholestea- } \\
\text { toma/cerebellopontine angle tumors } \\
\text { - Retrolabyrinthine presigmoid approach } \\
\text { - Vestibular neurectomy } \\
\text { - Vascular loop decompression }\end{array}$ & $\begin{array}{l}\text { Minor transient CSF leak (2), transient VI } \\
\text { nerve palsy ( } 1) \text {, } \\
\text { Intermediate CSF leak (1), } \\
\text { meningitis ( } 1 \text { ), transient III, IV,VI palsy (2), } \\
\text { X-XII paresis/paralysis (5)*, } \\
\text { Major VII } n \text { palsy HB grade IV-VI (6), } \\
\text { weak breathy voice (2), encephalocoele (2), } \\
\text { vision loss (1), cochleo-vestibular deficit (4), } \\
\text { death carotid blow-out (2), } \\
\text { amphotericin toxicity-renal failure }(1)^{\mathrm{b}}\end{array}$ \\
\hline
\end{tabular}

Abbreviations: ACC, Adenoid cystic carcinoma; CSF, cerebrospinal fluid; extn. extension; ICA, Internal Carotid Artery; inv., Involvement; plum., not present in the document; PNS, Paranasal sinus.

${ }^{a}$ Well rehabilitated speech and swallowing postsurgery was classified as an intermediate complication.

${ }^{b}$ Death due to amphotericin B nephrotoxicity, classified as a nonsurgical complication.

\section{Complications Encountered}

Among the 204 anterior skull-base procedures, a total of 23 surgical complications were noted (11\%). The endoscopic anterior skull-base group had 12 complications in 120 patients (10\%) with three major complications and no deaths. The external anterior skull-base group had 11 complications in 84 patients (13\%) with three major complications and one death.

Among the 125 lateral skull-base (external) procedures, a total of 41 surgical complications were encountered (33\%). The 41 complications included 4 minor, 16 intermediate, 19 major complications, and 2 surgical related deaths. One other death was classified as nonsurgical related (amphotericin B toxicity related acute renal failure) and not included in the analysis of surgical related complications. A significantly lower complication rate was noted in the anterior skullbase approaches (endoscopic + external) than in the lateral skull-base approaches $(p<0.001)$.
Deficits which were anticipated and expected prior to surgery were classified as sequelae rather than complications. Fifteen out of 18 cases with juvenile angiofibroma (IIIB) excised by the lateral subtemporal-infratemporal approach had section of the maxillary nerve, and were so classified.

Among 21 patients with normal presurgical facial nerve function and facial nerve transposition as part of a Fisch's type A excision, 15 recovered to grade III by the 9-month follow-up, and six had residual function worse than grade IV. The 15 patients with recovery to grade II and III were classified as sequelae rather than a complication.

12 patients had deterioration of lower cranial nerve function following surgery on the jugular foramen. Of them, 10/12 recovered function with compensation, speech, and swallowing therapy and a thyroplasty $(n=9)$. No patient required long-term tube feeds or a long-term tracheotomy. Two patients had residual weak voices, one of these despite a thyroplasty. Transient speech and swallowing 
Table 3 Surgical complications as per surgical approach and complexity

\begin{tabular}{|c|c|c|c|c|c|c|}
\hline & \multicolumn{2}{|l|}{ Level II } & \multicolumn{2}{|l|}{ Level III } & \multicolumn{2}{|l|}{ Level IV } \\
\hline & $\begin{array}{l}\text { Minor/ } \\
\text { intermediate }\end{array}$ & $\begin{array}{l}\text { Major/ } \\
\text { death }\end{array}$ & $\begin{array}{l}\text { Minor } / \\
\text { intermediate }\end{array}$ & $\begin{array}{l}\text { Major/ } \\
\text { death }\end{array}$ & $\begin{array}{l}\text { Minor } / \\
\text { intermediate }\end{array}$ & $\begin{array}{l}\text { Major/ } \\
\text { death }\end{array}$ \\
\hline \multicolumn{7}{|l|}{ Anterior skull-base } \\
\hline Anterior endoscopic endonasal, $n=120$ & $4 / 55$ & $0 / 55$ & $4 / 53$ & $1 / 53$ & $1 / 12$ & $2 / 12$ \\
\hline Anterior external, $n=84$ & $1 / 23$ & $0 / 23$ & $5 / 28$ & $1 / 28$ & $1 / 33$ & $3 / 33$ \\
\hline $\begin{array}{l}\text { Anterior endoscopic vs. anterior } \\
\text { external Chi-square test, } p \text {-value }\end{array}$ & 0.63 & - & 0.16 & 0.64 & 0.46 & 0.47 \\
\hline \multicolumn{7}{|l|}{ Lateral skull-base } \\
\hline Lateral external $n=125$ & $2 / 16$ & $0 / 16$ & $6 / 64$ & $4 / 64$ & $12 / 45$ & $17 / 45$ \\
\hline $\begin{array}{l}\text { Anterior external vs. at external } \\
\text { Chi-square test, } p \text {-value }\end{array}$ & 0.35 & - & 0.25 & 0.60 & 0.006 & 0.004 \\
\hline $\begin{array}{l}\text { Anterior (endoscopic + external) vs. } \\
\text { lateral Chi-square test, } p \text {-value }\end{array}$ & 0.40 & - & 0.73 & 0.26 & 0.004 & 0.003 \\
\hline
\end{tabular}

dysfunction which was ultimately well rehabilitated was classified as an intermediate complication (requires treatment but does not cause permanent disability)

Carotid blowouts occurred on three occasions, one intraoperative, and two in the first postoperative week. The intraoperative blow out was successfully treated with limited final morbidity but both patients with postoperative blow outs died.

\section{Analysis of Complications Depending on Surgical Approach and Surgical Complexity}

- Table 3 and - Fig. 1 depict the quantum of complications for differing surgical approaches and complexity of surgery (surgical levels). Level II procedures (endoscopic/anterior external/lateral external) were associated with occasional minor and intermediate complications but no major com-
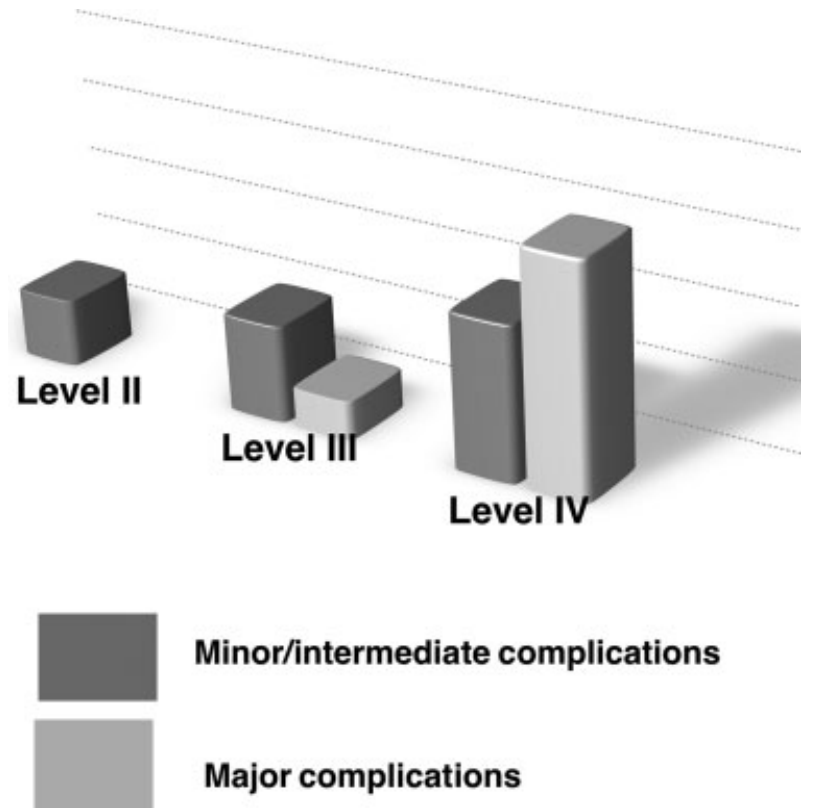

\section{Minor/intermediate complications}

\section{Major complications}

Fig. 1 Quantum of complications with increasing levels of surgical complexity. plications or deaths. Level III procedures led to some major complications but no deaths. All three deaths were associated with level IV procedures.

A trend is noted for major complications to be more manifest with increasing levels of surgical complexity (level II-IV; $p<0.05)$. Anterior skull-base endoscopic and external approaches did not differ in terms of complication rates across all levels of surgical complexity (-Table 3 ). Lateral approaches are noted to have similar complication rates as anterior approaches for level II and level III procedures but to have a greatly increased complication rate for level IV procedures.

\section{Discussion}

Surgical procedures on the skull-base have significant implications for the patient and there are occasions when some surgical morbidity is considered near-inevitable. It is naturally vital that surgical morbidity to be minimized and numerous individual advances in pretreatment radiology, adjuvant embolization, surgical instrumentation, anesthesia, and postsurgical intensive care have all contributed to cumulatively improve surgical care very significantly. ${ }^{12}$ The present evaluation from a contemporary practice includes all these individual aids and reports on the quantum of complications in the current era of skull-base surgery. Complications have been categorized by a clear and unambiguous classification system ${ }^{10}$ ( - Table $\mathbf{1}$ ) which is oriented toward patient outcomes rather than surgical procedures and is easily applied to diverse surgical procedures. Additionally, the large spectrum of skull-base procedures is categorized as per complexity and complication rates quantified for each subcategory.

The complication rate with anterior skull-base surgery is noted to be relatively lesser ( $11 \%$, total complications; $3 \%$, major complications; $0.5 \%$, death). Lateral skull-base surgery is noted to have a significantly higher complication rate (33\%, total complications; $15 \%$, major complications, $1.6 \%$, death; $p<0.001$ ). The vast majority of lateral skull-base complications are consequent to level IV procedures and level II and III 
procedures of the lateral skull-base are noted to be no more morbid than similarly categorized anterior skull-base procedures.

An integrated and unified grading of the complexity of skull-base surgical procedures is proposed (-Table 1). The classification is inspired from the widely quoted classification for endoscopic skull-base procedures from the Pittsburg's group ${ }^{9}$ and is adapted to be applied to the entire spectrum of skull-base procedures (endoscopic, open anterior, open lateral). Progressing from level II to level IV, a statistically significant progression is noted across all three surgical approaches of an increasing incidence of major complications and mortality (- Table 3 ). The progressive increase in complication rates are noted along increasing surgical levels is validation of the strength and appropriateness of the proposed categorization.

The original principle of skull-base surgery at its initiation was to "remove bone and so spare the brain." The initially developed transtemporal and infratemporal fossa procedures were developed as per this guiding principle. ${ }^{13-15}$ Wide bony dissection in the skull-base enabled excellent access to the dura and adjoining neurovascular structures with negligible brain retraction. Wide exposure further enabled closer access to the surgical site with shorter and proximally held instruments, thus leading to more precise and tremor free surgical work on the critical skull-base.

The advent of the endoscope with its illumination, magnification, and angled telescopes has added a new dimension to skull-base surgery. The endoscope provides for superior access and illumination but the surgical field is deeper and surgical dissection with longer instruments and narrow corridors can be technically challenging. Innovations in techniques, such as the "two surgeons-four hands" technique, the routine use of a vascularized nasoseptal flap for augmenting dural repairs, and new instrumentation (neuronavigation, intraoperative Doppler, endoscope holders, microdebrider, coblation, cavitron ultrasonic surgical aspirator [CUSA]) have enabled the development of a safe and effective procedure. ${ }^{16-19}$ Centers with significant experience have noted of reduced morbidity and reduced duration of hospital stay with the endoscopic approach as compared with the external approach ${ }^{2-4}$ but apprehensions have been expressed of a higher rate of cerebrospinal fluid (CSF) leaks with endoscopic procedures than with open procedures, especially so with procedures with higher grades of complexity. 2,20

As is noted in this analysis, approximately $42 \%$ of our throughput in skull-base today is either totally endoscopic or endoscopic assisted. On initial evaluation, endoscopic procedures seem to have lower complication rates than external procedures ( 9 vs. $35 \%, p<0.001$ ) but this is a consequence of endoscopic procedures being limited to the safer areas of the anterior skull-base. When looking at the anterior skull-base in isolation and evaluating complications, specifically with regard to the complexity of surgery, comparable complication rates are noted for endoscopic and external procedures of comparable surgical complexity (-Table 3 ).

A distinction has to be made between sequelae and complications. As a simple distinction, sequelae are expected adverse events, while complications are adverse events which can be potentially prevented. The differentiation between the two would probably be contentious. It would be expected that the informed consent would include a discussion of both but especially emphasize the inevitability/near-inevitability of the sequelae.

This analysis finds a much greater incidence of complications with lateral skull-base surgery. Additionally, this subgroup has a significant morbidity classified as sequelae rather than complications. Surgery on the jugular foramen is often associated with facial nerve dysfunction consequent to its surgical rerouting, and also lower cranial nerve dysfunction. Similarly, it is our experience that in patients with Radkowski's stage IIIB juvenile angiofibroma surgically accessed by the orbitozygomatic subtemporal-infratemporal approach, the VB nerve in its canal is an invariable casualty in the attempt to access tumor positioned medial to it in the Vidian canal complex, inferior and superior orbital fissures, paracavernous area, and sphenoid. In our practice, patients are specifically counseled regarding these deficits, and these are, therefore classified as sequelae rather than complications.

Rehabilitation and correction of residual deficits is an important part of skull-base practice. Such rehabilitation is best if undertaken immediately. In situations of facial nerve paralysis, our preference is to undertake immediate partial rehabilitation by upper eyelid loading (gold weight implantation) but nerve repair procedures take longer to be effective. Swallowing and speech rehabilitation in our practice is primarily undertaken by unilateral cricothyroid approximation (type IV thyroplasty) on the paralysed side. ${ }^{11}$ The deficits of a "high" vagal paralysis consequent to jugular foramen lesions include not only the horizontal vocal fold misalignment consequent to recurrent laryngeal nerve (RLN) paralysis but also additional deficits of vertical vocal fold misalignment, vocal fold hypotonia, and sensory loss consequent to superior laryngeal nerve paralysis (SLN). In this situation of a high vagal paralysis, cricothyroid approximation is noted to better correct these deficits than a type I thyroplasty as it better corrects the deficits of vocal fold hypotonia and vertical misalignment and also partially corrects for the horizontal plane glottic gap. ${ }^{11}$ Early interventions with cricothyroid approximation have contributed to minimizing swallowing morbidity in this report, with it being downgraded in many instances from being a major complication to an intermediate complication (i.e., a complication which requires treatment but does not cause permanent disability).

\section{Conclusions}

Many advances, surgical and nonsurgical, have contributed to the decreasing trends toward complications with skullbase surgery. Attention to rehabilitative procedures has further contributed toward this trend. In a contemporary otolaryngology led and primarily extradural skull-base practice, the overall total complication rate is currently noted at $19 \%$, and the major complication rate at $8 \%$. Mortality continues to be a reality and is noted at $1 \%$. Much greater complication rates are noted with lateral 
than with anterior skull-base surgery, particularly so with level IV procedures.

The categorization of surgical procedures and complications as proposed here enables an estimation of surgical morbidity and complication rates as per the complexity of the procedure. These should prove useful for informed consent and also in informed decisions regarding the risk-benefit of surgical procedures in individual situations.

\section{Conflicts of Interest}

None declared.

\section{References}

1 Svider PF, Baredes S, Eloy JA. Pitfalls in sinus surgery: an overview of complications. Otolaryngol Clin North Am 2015;48(05): 725-737

2 Fu TS, Monteiro E, Muhanna N, Goldstein DP, de Almeida JR. Comparison of outcomes for open versus endoscopic approaches for olfactory neuroblastoma: A systematic review and individual participant data meta-analysis. Head Neck 2016;38(Suppl 1): E2306-E2316

3 Nicolai P, Villaret AB, Bottazzoli M, Rossi E, Valsecchi MG. Ethmoid adenocarcinoma-from craniofacial to endoscopic resections: a single-institution experience over 25 years. Otolaryngol Head Neck Surg 2011;145(02):330-337

4 Meccariello G, Deganello A, Choussy O, et al. Endoscopic nasal versus open approach for the management of sinonasal adenocarcinoma: a pooled-analysis of 1826 patients. Head Neck 2016; 38(Suppl 1):E2267-E2274

5 Cunningham CD III, Friedman RA, Brackmann DE, Hitselberger WE, Lin HW. Neurotologic skull base surgery in pediatric patients. Otol Neurotol 2005;26(02):231-236

6 Patel SG, Singh B, Stambuk HE, et al. Craniofacial surgery for esthesioneuroblastoma: report of an international collaborative study. J Neurol Surg B Skull Base 2012;73(03):208-220

7 Miller JD, Taylor RJ, Ambrose EC, Laux JP, Ebert CS, Zanation AM. Complications of open approaches to the skull base in the endoscopic era. J Neurol Surg B Skull Base 2017;78(01):11-17
8 Kassam AB, Prevedello DM, Carrau RL, et al. Endoscopic endonasal skull base surgery: analysis of complications in the authors' initial 800 patients. J Neurosurg 2011;114(06):1544-1568

9 Snyderman C, Kassam A, Carrau R, Mintz A, Gardner P, Prevedello DM. Acquisition of surgical skills for endonasal skull base surgery: a training program. Laryngoscope 2007;117(04):699-705

10 Moffat DA. Recent Advances in Otolaryngology. Edinburgh: Churchill Livingstone; 1995:27-40

11 Thakar A, Sikka K, Verma R, Preetam C. Cricothyroid approximation for voice and swallowing rehabilitation of high vagal paralysis secondary to skull base neoplasms. Eur Arch Otorhinolaryngol 2011;268(11):1611-1616

12 Castelnuovo P, Dallan I, Battaglia P, Bignami M. Endoscopic endonasal skull base surgery: past, present and future. Eur Arch Otorhinolaryngol 2010;267(05):649-663

13 Zanoletti E, Martini A, Emanuelli E, Mazzoni A. Lateral approaches to the skull base. Acta Otorhinolaryngol Ital 2012;32(05): 281-287

14 Kong J, Yang HY, Wang YF, Yang HJ, Shen SY, Wang F. Surgical management and follow-up of lateral skull base tumors: an 8year review. Mol Clin Oncol 2017;6(02):214-220

15 Sanna M, Mancini F, Saleh E, Piazza P, Khrais T, Russo A, Taibah A. Approaches to infratemporal fossa. In: Atlas of Microsurgery of the Lateral Skull Base, 2nd ed. Stuttgart: Thieme; 2008:206-246

16 Wong GK, Poon WS, Lam MK. The impact of an armless frameless neuronavigation system on routine brain tumor surgery: a prospective analysis of 51 cases. Minim Invasive Neurosurg 2001;44 (02):99-103

17 Castelnuovo P, Pistochini A, Locatelli D. Different surgical approaches to the sellar region: focusing on the "two nostrils four hands technique". Rhinology 2006;44(01):2-7

18 Castelnuovo P, Battaglia P, Bignami M, et al. Endoscopic transnasal resection of anterior skull base malignancy with a novel 3D endoscope and neuronavigation. Acta Otorhinolaryngol Ital 2012;32(03):189-191

19 Tang H, Zhang H, Xie Q et al. Application of CUSA excel ultrasonic aspiration system in resection of skull base meningiomas. Chin J Cancer Res 2014;26(06):653-657

20 Zoli M, Guaraldi F, Pasquini E, Frank G, Mazzatenta D. The endoscopic endonasal management of anterior skull base meningiomas. J Neurol Surg B Skull Base 2018;79(Suppl 4):S300-S310 